\title{
Could MicroRNAs be Regulators of Gout Pathogenesis?
}

\author{
Yangang Wang ${ }^{\mathrm{a}}$ Donghua $\mathrm{Xu}^{\mathrm{b}}$ Bin Wang ${ }^{\mathrm{a}} \quad \mathrm{Xu} \mathrm{Hou}^{\mathrm{a}}$ \\ aDepartment of Endocrinology, Affiliated Hospital of Qingdao University, Qingdao, \\ ${ }^{b}$ Department of Rheumatology, Affiliated Hospital of Weifang Medical University, Weifang, China
}

\section{Key Words}

MicroRNAs • Gout • Pathogenesis

\begin{abstract}
MicroRNAs (miRNAs) are a class of noncoding RNAs that mainly negatively regulate gene expression. miRNAs have important roles in many diseases, including inflammatory diseases. Gout is a common arthritis caused by deposition of monosodium urate crystals within joints. Recent studies suggested that miRNAs may be involved in the development of inflammatory arthritis, including acute gouty arthritis. In the present review, we systemically discuss relevant publications in order to provide a better understanding on the possible role of miRNAs in gout. miRNAs may act as regulators of gout pathogenesis via several pathways. Targeting miRNAs may be a promisingstrategy in the treatment of gout.
\end{abstract}

Copyright $\odot 2015$ S. Karger AG, Basel

\section{Introduction}

Gout is a common arthritis caused by deposition of monosodium urate (MSU) crystals within joints and periarticular tissues after chronic hyperuricaemia [1]. It affects 1-2\% of adults in the world, and there is a consistent rise in the prevalence of gout in recent years, especially in developing countries [2]. Hyperuricemia is not a sufficient risk factor for the development of acute gouty arthritis, and there are several other important risk factors for

Y. Wang and D. Xu contributed equally to the work.

Yangang Wang, MD,

and $\mathrm{Xu} \mathrm{Hou}, \mathrm{MD}$ 
gout, such as obesity, hyperlipidaemia, and dietary factors [3]. MicroRNAs (miRNAs) are a class of noncoding RNAs that mainly negatively regulate gene expression [4]. miRNAs play an important role in human diseases, including some inflammatory diseases. Recent studies suggested that miRNAs may be involved in the development of inflammatory arthritis, including acute gouty arthritis [5, 6]. In resent review, we will systemically review relevant literatures to get a better understanding on the possible roles of miRNAs in gout.

\section{Overview of gout pathogenesis}

The pathogenesis of gout is still not well understood, and there is still lack of effective treatment for acute gouty arthritis [1, 2, 7]. MSU crystals can powerfully stimulate toll-like receptors and NLRP3 inflammasome, and further lead to complex inflammatory reaction (Fig. 1) [8]. In acute gouty arthritis, phagocytosis of MSU crystals in macrophages leads to the generation of reactive oxygen species (ROS) through activation of NADPH oxidases [8, 9]. Toll-like receptor 2 (TLR2) and toll-like receptor 4 (TLR4) on the macrophages are an integral part of the innate immune system and MSU crystals rigger innate immune responses via TLR2/TLR4, which further leads to inflammatory reaction [8, 9]. The initiating step in nucleotide-binding oligomerization domain (NOD)-like receptor containing pyrin domain 3 (NLRP3) activation is a priming signal by toll-like receptors that activate transcription of NLRP3 and pro-interleukin-1 $\beta$ (IL-1 $\beta$ ) through NF- $\kappa B$ (Fig. 1). Phagocytosis of monosodium urate (MSU) crystals will further activate the NLRP3 inflammasome, which consists of NLRP3, apoptosis-associated speck-like protein containing a caspase recruitment domain (ASC), and procaspase-1 (Fig. 1). The activation of NLRP3 inflammasome will lead to activation of caspase- 1 , which in turn cleaves pro-IL- $1 \beta$ to produce biologically active IL-1 $\beta$. Thus, MSU crystals finally lead to the production of and secretion of IL-1 $\beta$. IL- $1 \beta$ secretion can induce further production of IL-1 $\beta$ and other proinflammatory cytokines, such as tumor necrosis factor- $\alpha$ (TNF- $\alpha$ ), interleukin-8 (IL-8) and interleukin-6 (IL-6), which further lead to expanded inflammation (Fig. 1). IL-1 $\beta$ can bind to the IL-1 receptor on endothelial or synovial cells and result in signal transduction, which further leads to the production and secretion of adhesion molecules and chemokines (Fig. 1). Adhesion molecules and chemokines together result in subsequent inflammatory events including neutrophil recruitment and a series of intense inflammation.

\section{Overview of miRNAs}

miRNAs are evolutionarily-conserved endogenous non-coding RNAs that have been identified as post-transcriptional regulators of gene expression [10]. miRNAs are approximately 19-22 nucleotide single-stranded RNAs that regulate the stability of target messenger RNA by selective binding to specific sites [4]. Over 5000 miRNAs have now been identified, and miRNAs play an important role in a wide range of human diseases, including cancer, metabolic diseases, and inflammatory diseases. Recent studies suggested that miRNAs may be involved in the development of inflammatory arthritis, including acute gouty arthritis [5,6]. The miRNAs mainly bind to the 3 '-untranslated regions (3'UTR) of target mRNAs, resulting in mRNA degradation or the inhibition of mRNA translation [10]. Recent studies further show that miRNAs can bind to other regions of target mRNAs, resulting in translational repression or activation [10]. Previous studies have estimated that approximately $60 \%$ of protein-coding genes are modulated by miRNAs in either a single or multiple cellular pathways. miRNAs existing in a stable form in human body fluid, such as plasma, saliva, and urine, and thus are potential to be a biomarker of relevant diseases [4, 11]. It's no doubt that the clarification of miRNAs involved in the pathogenesis of gout might lead to a novel effective treatment. 
Fig. 1. Mechanisms of inflammation in acute gout.

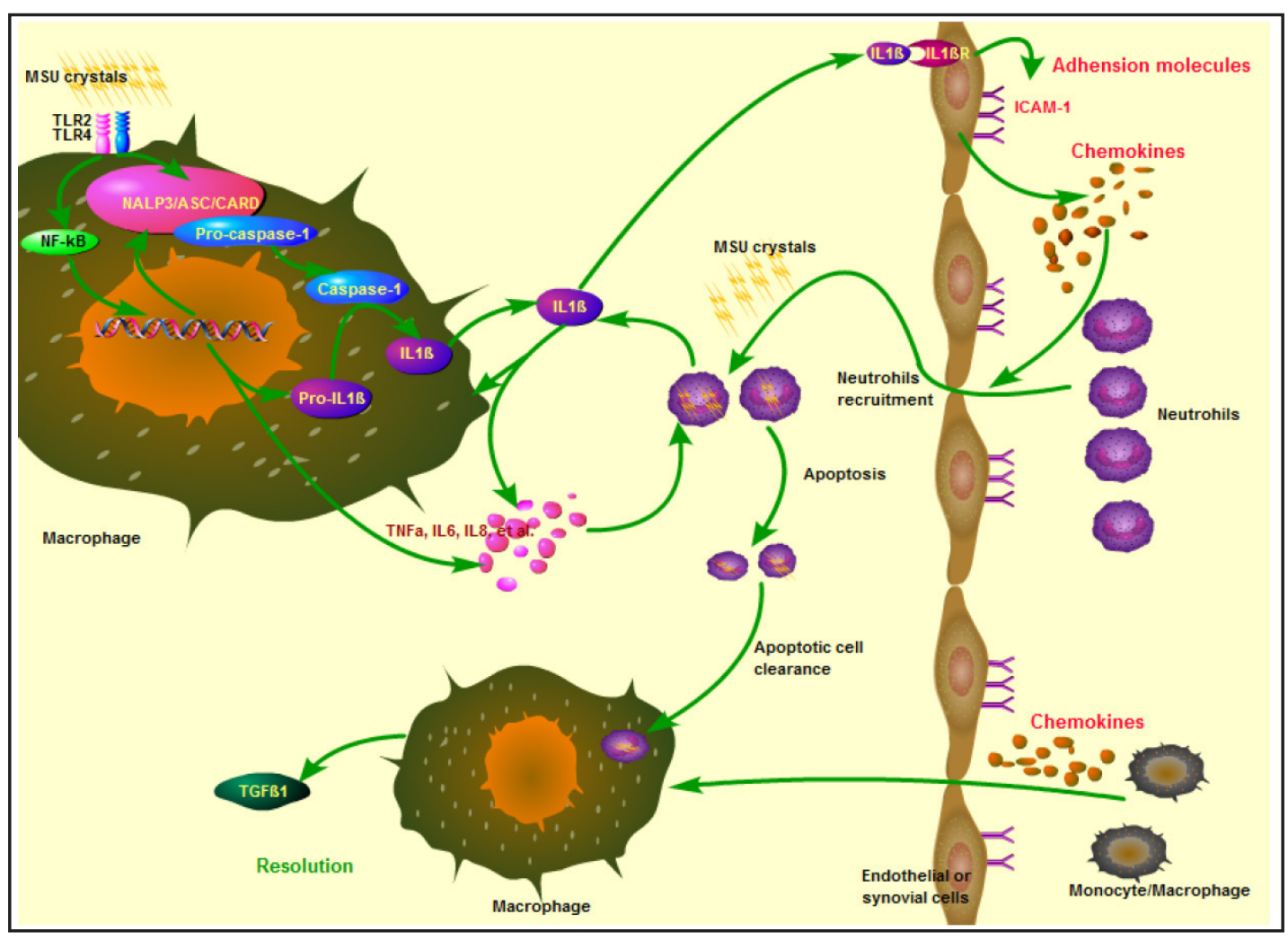

miRNAs and hyperuricaemia

Hyperuricaemia is a major risk factor of gout, and about $10 \%$ of patients with hyperuricaemia will suffer from gout [3]. In addition, hyperuricaemia is also an independent risk factor of a series of various diseases, including cardiovascular disease, stroke, and diabetes [11]. Currently, there are limited numbers of studies assessing the roles of miRNAs in hyperuricaemia. miR-34a can inhibit the expression of human urate anion exthanger 1 (URAT1) and reduce the excretion of uric acid $[12,13]$. Another study suggested that miR448 could target the xanthine oxidase (XO), which is a vital enzyme involving the production of uric acid [14]. Hyperuricaemia can down-regulate eNOS expression via miR-155 to induce endothelial dysfunction, and hyperuricaemia can stimulate the expression of miR-155 in endothelial cells [15]. However, there is no other miRNA reported to be involved with hyperuricaemia.

\section{miRNAs and toll-like receptors}

TLR2 and TLR4 on the macrophages are an integral part of the innate immune system and MSU crystals rigger innate immune response and inflammatory reaction via TLR2/ TLR4 (Fig. 1). Several miRNAs have been shown to directly target components of the TLR signalling system [9]. miR-144 can bound to 3'UTR of TLR2, and miR-144 can enhance TNF- $\alpha$ production by targeting TLR2 in non-alcoholic steatohepatitis (NASH) [16]. miR-154 and miR-143 can target TLR2 and inhibit the expression of TLR2 in colorectal cancer [17, 18]. miR-19a and miR-19b can target TLR2 mRNA, and decrease TLR2 protein expression in rheumatoid fibroblast-like synoviocytes [19]. miR-105 can modulate TLR2 protein expression in human oral keratinocytes [20]. miR-181c can suppress TLR4 by directly binding its 3'UTR in regulating the inflammatory response in oxygen-glucose-deprived 
microglia [21]. miR-146b can also modulate the TLR4 expression in inflammatory response [22]. Let-7b can target at TLR4 mRNA, and regulates the expression of the downstream genes related to the inflammation in H.pylori infection [23], while let-7i can down-regulate TLR4 expression in both coronary artery disease and epithelial immune responses to microbial infection $[24,25]$. miR-511 also can target TLR4 and is another potent modulator of immune response [26]. miR-146a can target TLR4 and further inhibit the activation of TLR4-dependent inflammatory cytokine secretion [27]. Though there are a large number of studies published to assess the roles of miRNAs in regulating TLR2/TLR4 expression in various diseases, there is no study assessing the relationship between miRNAs and TLR2/ TLR4 in gout. Additional studies investigating the roles of those miRNAs targeting TLR2/ TLR4 in gout are recommended.

\section{miRNAs and NLRP3 inflammasome}

The NLRP3 protein has emerged as a central regulator in the inflammatory process $[28,29]$. There is now clear evidence that MSU crystals trigger activation of the NLRP3/ ASC/caspase 1 inflammasome, which further lead to the production of IL-1 $\beta$. miR-223 can suppress NLRP3 expression through a conserved binding site within the 3'-UTR of NLRP3, reducing NLRP3 inflammasome activity [30]. miR-92a can indirectly activate the NLRP3 inflammasome by targeting key molecules in endothelial homeostasis, including Sirtuin 1, Kruppel-like factor 2 (KLF2), and KLF4 during oxidative stress [31]. However, there is no other miRNA identified to targeting NLRP3, and more studies are needed to further identify other possible miRNAs targeting NLRP3 inflammasome in inflammatory action. There is only one miRNA identified to control the ASC expression [32], and no microRNA to target caspase-1. Given the vital role of NLRP3 inflammasome for inflammatory diseases including gout, more researches on its modulation through miRNAs will help us get a better understanding of NLRP3 in gout and find potentially therapeutical target for gout.

\section{miRNAs and inflammatory cytokines}

IL-1 $\beta$ is a cytokine protein encoded by the IL1B gene. IL-1 $\beta$ precursor is cleaved by cytosolic caspase 1 to form mature IL-1 $\beta$. IL- $1 \beta$ has a central role in the regulation of immune and inflammatory responses to infections or sterile insults, and it also has a vital role in gout. However, there is no miRNA identified to target IL-1 $\beta$ from current literature. Previous studies have shown that miRNA-155 is a proinflammatory regulator via SHIP-1 downregulation in acute gouty arthritis, and overexpression of miR-155 can lead to suppress SHIP1 levels and enhance proinflammatory cytokines including IL-1 $\beta$ [5]. In other inflammatory diseases, miRNA-155 can also indirectly promote the production of IL-1 $\beta[33,34]$. There are also several miRNAs which can indirectly inhibit the production of IL-1 $\beta$, such as miR-146a miR-223, and miRNA-146b-5p [30, 35-39].

Currently, there are also no miRNAs identified to target TNF- $\alpha$, IL-8, or IL-6 in gout. Previous studies have found several miRNAs targeting TNF- $\alpha$ in other diseases, such as miR181s, miR181c, miR-19a, miR-155, miR-125b, and miR-130a [40-45]. Several miRNAs targeting IL-8 have also been identified in non-gout diseases, such as miR-106b, miR520b, miR-203 and miR-93 [46-49]. In addition, there are also several miRNAs targeting IL-6 in non-gout diseases, such as miR-98, miR-365 and let-7a [50-52]. Future studies may investigate whether the above miRNAs targeting TNF- $\alpha$, IL-8, or IL-6 in non-gout diseases also have some roles in the pathogenesis of gout.

\section{miRNAs and chemokines}

Chemokines are small proteins that play a crucial part in directing the movement of circulating mononuclearcells or leukocytes to sites of inflammation or injury [53]. Chemokines 
can regulate immune responses through the activation and recruitment of leukocytes. The approximately 50 human chemokines segregate into four families on the basis of differences in structure and function [53]. The most thoroughly characterized CC chemokine is monocyte chemoattractant protein 1 (MCP-1), termed "chemokine ligand CCL2" in the systematic nomenclature. Other CC chemokines include macrophage inflammatory protein (MIP)-1 $\alpha$ (CCL3) and MIP-1 $\beta$ (CCL4). Some CXC chemokines, of which interleukin-8 (CXCL8) is the classic type, attract polymorphonuclear leukocytes to sites of acute inflammation. There are a number of chemokines and their receptors identified to have some roles in acute gouty arthritis, such as CCL2, CCL3, CCL4, CXCL1,CXCL2, CXCL8(IL-8), CXCL10, CXCL16, CCR5, CXCR2, CXCR4, and CXCR6 [54-57].

Currently, there is also no miRNA identified to target chemokines in the development of gout. There are several miRNAs identified to target chemokines in other diseases. miR$125 \mathrm{~b}$ is a negative regulator of CCL4 and its reduction is partially responsible for the agerelated increase of CCL4 [58]. miR-495 could affect the proliferation and apoptosis of human umbilical vein endothelial cells by directly targeting CCL2 [59]. miR141 can regulate the expression of CXCL1 in lung cancer cells [60]. miR181b down-modulates CXCL1 and -2 through a direct binding to their 3'-UTR in breast cancer [61]. miR-141 regulates colonic leukocytic trafficking by targeting CXCL12 during murine colitis and human Crohn's disease [62]. miR-7641 can modulate the expression of CXCL1 during endothelial differentiation derived from human embryonic stem cells [63]. miR-126 bounds directly to the 3'-UTR of CCL2 mRNA, and overexpression of miR-126 in a human monocyte/macrophage cell line can attenuate CCL2 production [64]. miR-124a directly binds to the 3'-UTR of MCP-1 mRNA, and the induction of miR-124a in rheumatoid arthritis synoviocytes can significantly suppress the production of MCP-1 proteins [65]. However, the role of these miRNAs above targeting chemokines in the pathogenesis of gout is still unclear. Targeting chemokines through miRNAs is a promising strategy for the treatment of gout, and it deserves future studies.

\section{Summary}

The pathogenesis of gout is still not well understood now, and there is still lack of good and effective treatment for acute gouty arthritis. miRNAs have important roles in inflammatory diseases, and current literatures also show that they may act as important regulators of gout pathogenesis via several pathways. Given the importance of miRNAs for inflammatory diseases including gout, more studies on their roles in gout are needed, which will help us get a better understanding of gout pathogenesis and develop some promising effective treatments for gout [66].

\section{Disclosure Statement}

All authors declare that they have no conflicts of interest.

\section{References}

1 Richette P, Bardin T: Gout. Lancet 2010;375:318-328.

2 Neogi T: Clinical practice. Gout. N Engl J Med 2011;364:443-452.

3 Roddy E, Mallen CD, Doherty M: Gout. BMJ 2013;347:f5648.

4 O'Connell RM, Rao DS, Chaudhuri AA, Baltimore D: Physiological and pathological roles for micrornas in the immune system. Nat Rev Immunol 2010;10:111-122.

5 Jin HM, Kim TJ, Choi JH, Kim MJ, Cho YN, Nam KI, Kee SJ, Moon JB, Choi SY, Park DJ, Lee SS, Park YW: Microrna-155 as a proinflammatory regulator via ship-1 down-regulation in acute gouty arthritis. Arthritis Res Ther 2014;16:R88. 


\section{Cellular Physiology Cell Physiol Biochem 2015;36:2085-2092 \begin{tabular}{l|l|l}
\hline DOI: 10.1159/000430176 & (C) 2015 S. Karger AG, Basel
\end{tabular} and Biochemistry Published online: July 21, 2015 \\ Wang et al.: MicroRNAs and Gout}

6 Alevizos I, Illei GG: Micrornas as biomarkers in rheumatic diseases. Nat Rev Rheumatol 2010;6:391-398.

7 Burns CM, Wortmann RL: Gout therapeutics: New drugs for an old disease. Lancet 2011;377:165-177.

8 Busso N, So A: Mechanisms of inflammation in gout. Arthritis Res Ther 2010;12:206.

9 Quinn SR, O'Neill LA: A trio of micrornas that control toll-like receptor signalling. Int Immunol 2011;23:421-425.

10 Ha M, Kim VN: Regulation of microrna biogenesis. Nat Rev Mol Cell Biol 2014;15:509-524.

11 Ameres SL, Zamore PD: Diversifying microrna sequence and function. Nat Rev Mol Cell Biol 2013;14:475488.

12 Sun WF, Zhu MM, Li J, Zhang XX, Liu YW, Wu XR, Liu ZG: Effects of xie-zhuo-chu-bi-fang on mir-34a and urat1 and their relationship in hyperuricemic mice. J Ethnopharmacol 2015;161:163-169.

13 Sun WF, Zhang XX, Sun FY, Xu W, Liang J, Feng SM, Wang T: Microrna expression patterns of the kidney in hyperuricemia mice treated with xiezhuo chubi decoction. Chin J Integr Med 2011;17:35-42.

14 Knake C, Stamp L, Bahn A: Molecular mechanism of an adverse drug-drug interaction of allopurinol and furosemide in gout treatment. Biochem Biophys Res Commun 2014;452:157-162.

15 Zhang X, Hong Q, Hou K, Wang Y, Wu D, Chen X: [high concentration uric acid regulates endothelial function via mir-155]. Nan Fang Yi Ke Da Xue Xue Bao 2013;33:1141-1145.

16 Li D, Wang X, Lan X, Li Y, Liu L, Yi J, Li J, Sun Q, Wang Y, Li H, Zhong N, Holmdahl R, Lu S: Down-regulation of mir-144 elicits proinflammatory cytokine production by targeting toll-like receptor 2 in nonalcoholic steatohepatitis of high-fat-diet-induced metabolic syndrome e3 rats. Mol Cell Endocrinol 2014;402C:1-12.

17 Xin C, Zhang H, Liu Z: Mir-154 suppresses colorectal cancer cell growth and motility by targeting tlr2. Mol Cell Biochem 2014;387:271-277.

18 Guo H, Chen Y, Hu X, Qian G, Ge S, Zhang J: The regulation of toll-like receptor 2 by mir-143 suppresses the invasion and migration of a subset of human colorectal carcinoma cells. Mol Cancer 2013;12:77.

19 Philippe L, Alsaleh G, Suffert G, Meyer A, Georgel P, Sibilia J, Wachsmann D, Pfeffer S: Tlr2 expression is regulated by microrna mir-19 in rheumatoid fibroblast-like synoviocytes. J Immunol 2012;188:454-461.

20 Benakanakere MR, Li Q, Eskan MA, Singh AV, Zhao J, Galicia JC, Stathopoulou P, Knudsen TB, Kinane DF: Modulation of tlr2 protein expression by mir-105 in human oral keratinocytes. J Biol Chem 2009;284:23107-23115.

21 Zhang L, Li YJ, Wu XY, Hong Z, Wei WS: Microrna-181c negatively regulates the inflammatory response in oxygen-glucose-deprived microglia by targeting toll-like receptor 4. J Neurochem 2015;132:713-723.

22 Curtale G, Mirolo M, Renzi TA, Rossato M, Bazzoni F, Locati M: Negative regulation of toll-like receptor 4 signaling by il-10-dependent microrna-146b. Proc Natl Acad Sci U S A 2013;110:11499-11504.

23 Teng GG, Wang WH, Dai Y, Wang SJ, Chu YX, Li J: Let-7b is involved in the inflammation and immune responses associated with helicobacter pylori infection by targeting toll-like receptor 4. PLoS One 2013;8:e56709.

24 Satoh M, Tabuchi T, Minami Y, Takahashi Y, Itoh T, Nakamura M: Expression of let-7i is associated with tolllike receptor 4 signal in coronary artery disease: Effect of statins on let-7i and toll-like receptor 4 signal. Immunobiology 2012;217:533-539.

25 Chen XM, Splinter PL, O'Hara SP, LaRusso NF: A cellular micro-rna, let-7i, regulates toll-like receptor 4 expression and contributes to cholangiocyte immune responses against cryptosporidium parvum infection. J Biol Chem 2007;282:28929-28938.

26 Tserel L, Runnel T, Kisand K, Pihlap M, Bakhoff L, Kolde R, Peterson H, Vilo J, Peterson P, Rebane A: Microrna expression profiles of human blood monocyte-derived dendritic cells and macrophages reveal mir-511 as putative positive regulator of toll-like receptor 4. J Biol Chem 2011;286:26487-26495.

27 Yang K, He YS, Wang XQ Lu L, Chen QJ, Liu J, Sun Z, Shen WF: Mir-146a inhibits oxidized low-density lipoprotein-induced lipid accumulation and inflammatory response via targeting toll-like receptor 4. FEBS Lett 2011;585:854-860.

28 Vande Walle L, Van Opdenbosch N, Jacques P, Fossoul A, Verheugen E, Vogel P, Beyaert R, Elewaut D, Kanneganti TD, van Loo G, Lamkanfi M: Negative regulation of the nlrp3 inflammasome by a20 protects against arthritis. Nature 2014;512:69-73.

29 Schroder K, Zhou R, Tschopp J: The nlrp3 inflammasome: A sensor for metabolic danger? Science 2010;327:296-300. 
30 Haneklaus M, Gerlic M, Kurowska-Stolarska M, Rainey AA, Pich D, McInnes IB, Hammerschmidt W, O'Neill LA, Masters SL: Cutting edge: Mir-223 and ebv mir-bart15 regulate the nlrp3 inflammasome and il-1beta production. J Immunol 2012;189:3795-3799.

31 Chen Z, Wen L, Martin M, Hsu CY, Fang L, Lin FM, Lin TY, Geary MJ, Geary G, Zhao Y, Johnson DA, Chen JW, Lin SJ, Chien S, Huang HD, Miller YI, Huang PH, Shyy JY: Oxidative stress activates endothelial innate immunity via sterol regulatory element binding protein 2 (srebp2) transactivation of mirna-92a. Circulation 2015;131:805-814.

32 Momeni M1, Reza Mirzaei M, Zainodini N, Hassanshahi G, Arababadi MK: MiR-143 induces expression of AIM2 and ASC in Jurkat cell line. Iran J Immunol. 2013;10:103-109.

33 Li X, Tian F, Wang F: Rheumatoid arthritis-associated microrna-155 targets socs1 and upregulates tnfalpha and il-1beta in pbmcs. Int J Mol Sci 2013;14:23910-23921.

34 Ceppi M, Pereira PM, Dunand-Sauthier I, Barras E, Reith W, Santos MA, Pierre P: Microrna-155 modulates the interleukin-1 signaling pathway in activated human monocyte-derived dendritic cells. Proc Natl Acad Sci U S A 2009;106:2735-2740.

35 Yang CR, Shih KS, Liou JP, Wu YW, Hsieh IN, Lee HY, Lin TC, Wang JH: Denbinobin upregulates mir146a expression and attenuates il-1beta-induced upregulation of icam-1 and vcam-1 expressions in osteoarthritis fibroblast-like synoviocytes. J Mol Med (Berl) 2014

36 Wang JH, Shih KS, Wu YW, Wang AW, Yang CR: Histone deacetylase inhibitors increase microrna-146a expression and enhance negative regulation of interleukin-1 beta signaling in osteoarthritis fibroblast-like synoviocytes. Osteoarthritis Cartilage 2013;21:1987-1996.

37 Xie YF, Shu R, Jiang SY, Liu DL, Ni J, Zhang XL: Microrna-146 inhibits pro-inflammatory cytokine secretion through il-1 receptor-associated kinase 1 in human gingival fibroblasts. J Inflamm (Lond) 2013;10:20.

38 Chen Q, Wang H, Liu Y, Song Y, Lai L, Han Q Cao X, Wang Q: Inducible microrna-223 down-regulation promotes tlr-triggered il-6 and il-1beta production in macrophages by targeting stat3. PLoS One 2012;7:e42971.

39 Li J, Huang J, Dai L, Yu D, Chen Q Zhang X, Dai K: Mir-146a, an il-1beta responsive mirna, induces vascular endothelial growth factor and chondrocyte apoptosis by targeting smad4. Arthritis Res Ther 2012;14:R75.

40 Dan C, Jinjun B, Zi-Chun H, Lin M, Wei C, Xu Z, Ri Z, Shun C, Wen-Zhu S, Qing-Cai J, Wu Y: Modulation of tnfalpha mrna stability by human antigen $r$ and mir181s in sepsis-induced immunoparalysis. EMBO Mol Med 2014;7:140-157.

41 Zhang J, Wu H, Li P, Zhao Y, Liu M, Tang H: Nf-kappab-modulated mir-130a targets tnf-alpha in cervical cancer cells. J Transl Med 2014;12:155.

42 Chen B, She S, Li D, Liu Z, Yang X, Zeng Z, Liu F: Role of mir-19a targeting tnf-alpha in mediating ulcerative colitis. Scand J Gastroenterol 2013;48:815-824.

43 Rio P, Agirre X, Garate L, Banos R, Alvarez L, San Jose-Eneriz E, Badell I, Casado JA, Garin M, Prosper F, Bueren JA: Down-regulated expression of hsa-mir-181c in fanconi anemia patients: Implications in tnfalpha regulation and proliferation of hematopoietic progenitor cells. Blood 2012;119:3042-3049.

44 Bala S, Marcos M, Kodys K, Csak T, Catalano D, Mandrekar P, Szabo G: Up-regulation of microrna-155 in macrophages contributes to increased tumor necrosis factor \{alpha\} (tnf\{alpha\}) production via increased mrna half-life in alcoholic liver disease. J Biol Chem 2011;286:1436-1444.

45 Tili E, Michaille JJ, Cimino A, Costinean S, Dumitru CD, Adair B, Fabbri M, Alder H, Liu CG, Calin GA, Croce CM: Modulation of mir-155 and mir-125b levels following lipopolysaccharide/tnf-alpha stimulation and their possible roles in regulating the response to endotoxin shock. J Immunol 2007;179:5082-5089.

46 Fabbri E, Borgatti M, Montagner G, Bianchi N, Finotti A, Lampronti I, Bezzerri V, Dechecchi MC, Cabrini G, Gambari R: Expression of microrna-93 and interleukin-8 during pseudomonas aeruginosa-mediated induction of proinflammatory responses. Am J Respir Cell Mol Biol 2014;50:1144-1155.

47 Wei T, Xu N, Meisgen F, Stahle M, Sonkoly E, Pivarcsi A: Interleukin-8 is regulated by mir-203 at the posttranscriptional level in primary human keratinocytes. Eur J Dermatol 2013

48 Chuang TD, Luo X, Panda H, Chegini N: Mir-93/106b and their host gene, mcm7, are differentially expressed in leiomyomas and functionally target $\mathrm{f3}$ and il-8. Mol Endocrinol 2012;26:1028-1042.

49 Hu N, Zhang J, Cui W, Kong G, Zhang S, Yue L, Bai X, Zhang Z, Zhang W, Zhang X, Ye L: Mir-520b regulates migration of breast cancer cells by targeting hepatitis b x-interacting protein and interleukin-8. J Biol Chem 2011;286:13714-13722. 


\section{Cellular Physiology Cell Physiol Biochem 2015;36:2085-2092

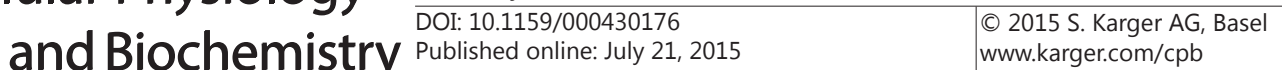 \\ Wang et al.: MicroRNAs and Gout}

50 Li F, Li XJ, Qiao L, Shi F, Liu W, Li Y, Dang YP, Gu WJ, Wang XG: Mir-98 suppresses melanoma metastasis through a negative feedback loop with its target gene il-6. Exp Mol Med 2014;46:e116.

51 Chafin CB, Regna NL, Dai R, Caudell DL, Reilly CM: Microrna-let-7a expression is increased in the mesangial cells of nzb/w mice and increases il-6 production in vitro. Autoimmunity 2013;46:351-362.

52 Xu Z, Xiao SB, Xu P, Xie Q, Cao L, Wang D, Luo R, Zhong Y, Chen HC, Fang LR: Mir-365, a novel negative regulator of interleukin- 6 gene expression, is cooperatively regulated by sp 1 and nf-kappab. J Biol Chem 2011;286:21401-21412.

53 Charo IF, Ransohoff RM: The many roles of chemokines and chemokine receptors in inflammation. N Engl J Med 2006;354:610-621.

54 Schauer C, Janko C, Munoz LE, Zhao Y, Kienhofer D, Frey B, Lell M, Manger B, Rech J, Naschberger E, Holmdahl R, Krenn V, Harrer T, Jeremic I, Bilyy R, Schett G, Hoffmann M, Herrmann M: Aggregated neutrophil extracellular traps limit inflammation by degrading cytokines and chemokines. Nat Med 2014;20:511-517.

55 Lee EY, Lee ZH, Song YW: The interaction between cxcl10 and cytokines in chronic inflammatory arthritis. Autoimmun Rev 2013;12:554-557.

56 Ruth JH, Arendt MD, Amin MA, Ahmed S, Marotte H, Rabquer BJ, Lesch C, Lee S, Koch AE: Expression and function of cxcl16 in a novel model of gout. Arthritis Rheum 2010;62:2536-2544.

57 Scanu A, Luisetto R, Oliviero F, Gruaz L, Sfriso P, Burger D, Punzi L: High-density lipoproteins inhibit urate crystal-induced inflammation in mice. Ann Rheum Dis 2015;74:587-594.

58 Cheng NL, Chen X, Kim J, Shi AH, Nguyen C, Wersto R, Weng NP: Microrna-125b modulates inflammatory chemokine ccl4 expression in immune cells and its reduction causes ccl4 increase with age. Aging Cell 2015;14:200-208.

59 Liu D, Zhang XL, Yan CH, Li Y, Tian XX, Zhu N, Rong JJ, Peng CF, Han YL: Microrna-495 regulates the proliferation and apoptosis of human umbilical vein endothelial cells by targeting chemokine ccl2. Thromb Res 2015;135:146-154.

60 Lv M, Xu Y, Tang R, Ren J, Shen S, Chen Y, Liu B, Hou Y, Wang T: Mir141-cxcl1-cxcr2 signaling-induced treg recruitment regulates metastases and survival of non-small cell lung cancer. Mol Cancer Ther 2014;13:3152-3162.

61 Kronski E, Fiori ME, Barbieri O, Astigiano S, Mirisola V, Killian PH, Bruno A, Pagani A, Rovera F, Pfeffer U, Sommerhoff CP, Noonan DM, Nerlich AG, Fontana L, Bachmeier BE: Mir181b is induced by the chemopreventive polyphenol curcumin and inhibits breast cancer metastasis via down-regulation of the inflammatory cytokines cxcl1 and -2. Mol Oncol 2014;8:581-595.

62 Huang Z, Shi T, Zhou Q, Shi S, Zhao R, Shi H, Dong L, Zhang C, Zeng K, Chen J, Zhang J: Mir-141 regulates colonic leukocytic trafficking by targeting cxcl12 beta during murine colitis and human crohn's disease. Gut 2014;63:1247-1257.

63 Yoo JK, Jung HY, Kim CH, Son WS, Kim JK: Mir-7641 modulates the expression of cxcl1 during endothelial differentiation derived from human embryonic stem cells. Arch Pharm Res 2013;36:353-358.

64 Arner E, Mejhert N, Kulyte A, Balwierz PJ, Pachkov M, Cormont M, Lorente-Cebrian S, Ehrlund A, Laurencikiene J, Heden P, Dahlman-Wright K, Tanti JF, Hayashizaki Y, Ryden M, Dahlman I, van Nimwegen E, Daub CO, Arner P: Adipose tissue micrornas as regulators of ccl2 production in human obesity. Diabetes 2012;61:1986-1993.

65 Kawano S, Nakamachi Y: Mir-124a as a key regulator of proliferation and mcp-1 secretion in synoviocytes from patients with rheumatoid arthritis. Ann Rheum Dis 2011;70:i88-91.

66 Li Z, Rana TM: Therapeutic targeting of micrornas: Current status and future challenges. Nat Rev Drug Discov 2014;13:622-638. 